\title{
Study of the potential of near-infrared reflectance spectroscopy in the analysis of the tree foliage intake of goats
}

\author{
JJ Waelput ${ }^{1}$, R Biston'1, M Meuret ${ }^{2}$ \\ 1 CRA, Gembloux, Station de Haute Belgique, 100 rue du Serpont 6600, Libramont, Belgium; \\ 2 INRA, SAD Unité d'Ecodéveloppement, Domaine Saint-Paul, 84140 Montfavet, France
}

Introduction - The aim of this study, one of the first in a series, was to determine whether near-infrared reflectance spectroscopy (NIRS) could be of future use in the analysis of the food intake of goats on Mediterranean wooded rangelands.

Materials and Methods - Fodder and focal samples were collected from 3 groups of 3 goats, browsing ad lib on fresh leafy Quercus pubescens branches. The 3 groups were made up of: 3 dried-up animals without supplementation; 3 lactating animals, supplemented with a urea-molasses mixture, in a digestibility cage (Meuret, 1988); and 3 lactating animals compelled to eat a pure $Q$ pubescens diet on rangeland, and supplemented with a urea-battey mixture (Waelput, 1988). The separated leaves (no of samples $=100)$, stems and fruits $(n o=50)$ of $Q$ pubescens, the corresponding feces (no = 700 ), and the leaves of 4 other shrub samples which can be consumed on the same rangeland (Hedera helix, Quercus ilex, Pistacia terebinthus and Cornus sanguinea) were dried in a ventilated oven at $60^{\circ} \mathrm{C}$ until a constant weight was reached, and then ground with a standard hammer-mill ( $1 \mathrm{~mm}$ sieve). These first results concern the analysis of organic matter (OM) and lignin (Li) (Christian, 1971) by wet procedure (WP) and NIRS (PSCO, RCA 6250).

Results and Discussion - The organic matter (OM in \% DM) and lignin content $(\mathrm{Li}$ in \% OM) obtained from WP are respectively (mean \pm SD) $Q$ pubescens leaves $(94.3 \pm 0.6 ; 10.8 \pm 0.8)$, stems and immature fruit $(95.0 \pm 1.2 ; 23.1 \pm 1.4)$, other shrub leaves $(91.7 \pm 3.8 ; 10.8 \pm 6.8)$ and feces $(90.5 \pm 1.3 ; 17.7 \pm 1.1)$. The correlations $\left(R^{2}\right)$ for calibration equations between WP and NIRS for $Q$ pubescens leaves alone are for $\mathrm{OM}$ and $\mathrm{Li}$ respectively 0.92 and 0.93 (standard error of calibration, $S E C=0.22$ and 0.46 ). As all the forage samples are included in the calibration, the correlation is improved for lignin: $R^{2}=0.98$ and $S E C=0.81$. The calibration of fecal samples shows that it is not necessary to develop 3 separate equations: $R^{2}=0.86$ and $S E C=0.42$. WP values of fecal samples were predicted from NIRS: $R^{2}=0.93$ and standard error of prediction $=0.29$.

The accuracy of the NIRS procedure seems to make it an acceptable method for providing rapid determinations of the quality of available forage and diet on wooded rangeland, although confirmation through further analysis is necessary.

Christian KR (1971) Field Stn Rec Div PI Ind CSIRO (Aust) 10, 29-34

Meuret M (1988) Small Rumin Res 1, 273-290

Waelput JJ (1988) Mém Ing Agro Gembloux 